\title{
DIREITO AMBIENTAL E AS DIVERSIDADES NATURAL E CULTURAL NO BRASIL: DIREITOS DA SOCIOBIODIVERSIDADE E SUSTENTABILIDADE NA CONSTITUIÇÃO BRASILEIRA
}

\author{
ENVIRONMENTAL LAW AND NATURAL AND CULTURAL DIVERSITY IN \\ BRAZIL: SOCIOBIODIVERSITY RIGHTS AND SUSTAINABILITY IN BRAZILIAN \\ CONSTITUTION
}

Larissa Nunes Cavalheiro*

Luiz Ernani Bonesso de Araujo **

\begin{abstract}
Resumo: Este artigo expõe a temática acerca das diversidades natural e cultural a partir de uma leitura do cenário sociobiodiverso brasileiro com os dispositivos constitucionais que refletem esta realidade de país megabiodiverso e detentor de uma multiplicidade de culturas e que devem ser refletidos pelo Direito Ambiental de forma integrada. Para tanto, inicia-se evidenciando o artigo 225 da Lei Maior brasileira, que trata do meio ambiente natural, destacando a biodiversidade e a sua devida proteção. No segundo momento deste artigo, ressalta-se a diversidade cultural do Brasil, a partir da exposição dos artigos 215 e 216 da Lei Maior brasileira, que traz os contornos do meio ambiente cultural. Após estes apontamentos, o terceiro momento do presente trabalho intenta realizar uma aproximação entre sociobiodiversidade e sustentabilidade, para tornar esta um paradigma de desenvolvimento em consonância com o reconhecimento e proteção das referidas diversidades, garantindo o direito ao meio ambiente ecologicamente equilibrado e a valorização das diferentes culturas e seus saberes vinculados à biodiversidade - sociobiodiversidade. Quanto aos métodos utilizados para a elaboração do presente artigo, foi utilizado o dedutivo enquanto abordagem e o monográfico enquanto procedimento. Optou-se pelo primeiro, pois a partir da relação entre os dispositivos constitucionais que tratam do meio ambiente natural e cultural, se pretendeu chegar a uma conclusão mais ampla, envolvendo os conceitos de sociobiodiversidade e sustentabilidade. Quanto a opção pelo segundo método, esta se deu em decorrência da pretensão em analisar o tema aqui proposto em profundidade, observando seus diferentes aspectos - jurídico e socioambiental -, de modo a explicá-lo de maneira mais integrada e analítica possível.
\end{abstract}

Palavras-chave: Direito Ambiental; Diversidade; Sociobiodiversidade; Sustentabilidade.

\footnotetext{
* Mestranda do Programa de Pós-Graduação em Direito da Universidade Federal de Santa Maria (UFSM), área de concentração "Direitos Emergentes da Sociedade Global", vinculada a linha de pesquisa "Direitos da Sociobiodiversidade e Sustentabilidade. Bolsista CAPES. Membro do Grupo de Pesquisa em Direito da Sociobiodiversidade (GPDS/UFSM). Especialista em Direito Público pela Escola Superior da Magistratura Federal (ESMAFE/RS). Especialista em Educação Ambiental pela UFSM. Graduada em Direito pelo Centro Universitário Franciscano (UNIFRA). Santa Maria, Rio Grande do Sul, Brasil. Email: laranunes7@ hotmail.com ** Professor Associado do Departamento de Direito da Universidade Federal de Santa Maria (UFSM). Coordenador e Professor do Programa de Pós-Graduação - Mestrado em Direito da UFSM. Doutor e Mestre em Direito pela Universidade Federal de Santa Catarina (UFSC). Líder e Pesquisador do Grupo de Pesquisa em Direito da Sociobiodiversidade (GPDS/UFSM). Santa Maria, Rio Grande do Sul, Brasil. E-mail: luiz.bonesso@gmail.com
} 
Abstract: This article exposes the theme about the natural and cultural diversity from a reading of the Brazilian sociobiodiverse scenario with the constitutional provisions that reflect this reality megabiodiverse country and a multiplicity of cultures holder and that should be reflected by the Environmental Law seamlessly. For that, starts showing article 225 of the Brazilian Higher Law, which deals with the natural environment, biodiversity and stressing its necessary protection. On the second moment of this article, stands out the cultural diversity of Brazil, from the exposure of articles 215 and 216 of the Brazilian Higher Law, which brings the contours of the cultural environment. After these appointments, the third moment of the present work tries conduct a approach between sociobiodiversity and sustainability, to make this a paradigm of development in accordance with the recognition and protection of these diversities, guaranteeing the right to an ecologically balanced environment and the appreciation of different cultures and their knowledge related to biodiversity sociobiodiversity. As to the methods used in the preparation of this article, while the deductive approach and the monographic while procedure was used. We opted for the first, because it from the relationship between the constitutional provisions dealing with the natural and cultural environment, it was intended to reach a broader conclusion, involving the concepts of sociobiodiversity and sustainability. As the option for the second method, this occurred as a result of the claim to analyze the theme presented here in depth, noting its different aspects - legal, social-environmental - in order to explain it in a more integrated and analytical manner possible.

Keywords: Environmental Law; Diversity; Sociobiodiversity; Sustainability.

\section{INTRODUÇÃO}

Diante da vinculação entre biodiversidade e diferentes culturas, delineia-se o conceito de sociobiodiversidade numa apreensão integrada entre os recursos naturais e os modos de vidas sustentáveis, ou seja, das implicações ecológico-sociais que decorrem deste cenário. Este contexto é uma realidade de países megabiodiversos, dentre eles, o de maior destaque é o Brasil, que em sua Lei Maior - Constituição Federal de 1988 - traz dispositivos que atentam para esta condição sociobiodiversa. Diante desta apreensão, que se objetivou expor alguns dispositivos constitucionais que em seu conteúdo refletem a diversidade natural e a diversidade cultural brasileira, para em momento posterior ressaltar a proximidade da sociobiodiversidade e sustentabilidade e a sua necessária vinculação para efetivar o reconhecimento e proteção constitucionais das referidas diversidades.

Para tanto, o presente trabalho foi estruturado em três momentos, partindo da inquietação acerca da realidade brasileira, qual seja, um país rico em diversidades naturais e culturais, devendo ambas ser reconhecidas e protegidas, pois compõe a identidade e potencial brasileiro, sendo possível elevar a condição do país enquanto modelo de desenvolvimento sustentável a partir da apreensão da sua sociobiodiversidade. 
Direito Ambiental e as Diversidades Natural e Cultural no Brasil: direitos da Sociobiodiversidade e Sustentabilidade na Constituição Brasileira

Assim, no primeiro momento foram expostos dispositivos constitucionais brasileiros que refletem a diversidade natural - biodiversidade -, ou seja, o meio ambiente natural e a sua necessária proteção, sendo um dos elementos que compõe o conceito e cenário da sociobiodversidade. Da mesma forma, integra um dos pilares fundamentais da sustentabilidade, qual seja, o ambiental, que denota o direito ao meio ambiente ecologicamente equilibrado, tanto no presente, quanto no futuro. Ocorre que, neste meio ambiente natural está inserida a diversidade de culturas, que forma o meio ambiente cultural brasileiro, objeto do próximo momento deste trabalho.

Quando se trata da diversidade cultural, a Lei Maior brasileira traz em seu conteúdo o reconhecimento da riqueza cultural que decorre dos diferentes modos de vida, muitos deles sustentáveis, pois em harmonia com o ciclo natural do meio em que estão inseridos. Estes modos revelam conhecimentos dos povos tradicionais atrelados à biodiversidade. Partindo da importância deste contexto, que se expõe os artigos 215 e 216 da Constituição Federal brasileira de 1988, conteúdo este que compõe o segundo momento deste trabalho. Revela-se o aspecto social-cultural da sustentabilidade e a importância em reconhecer, proteger e perpetuar a diversidade cultural, pois dela diferentes conhecimentos contribuem para o uso sustentável da biodiversidade, além de identificarem toda a existência de uma população tradicional.

Fechando o desenvolvimento do presente trabalho, o terceiro momento intenta realizar a aproximação entre a sociobiodversidade e sustentabilidade, uma vez que do cenário do primeiro conceito decorrem direitos a serem considerados pela segunda enquanto desenvolvimento. Neste sentido, impõe-se um paradigma sustentável em consonância com as diversidades - natural e cultural -, denotando a apreensão da sociobiodiversidade para delinear um desenvolvimento condizente com a realidade brasileira. Assim, o direito ao meio ambiente ecologicamente equilibrado é assegurado a todos, a partir de uma percepção sociobiodiversa da sustentabilidade.

Quanto aos métodos utilizados para a elaboração do presente artigo, foi utilizado o dedutivo enquanto abordagem e o monográfico enquanto procedimento. Optou-se pelo primeiro, pois a partir da relação entre os dispositivos constitucionais que tratam do meio ambiente natural e cultural, se pretendeu chegar a uma conclusão mais ampla, envolvendo os conceitos de sociobiodiversidade e sustentabilidade. Quanto a opção pelo segundo método, esta se deu em decorrência da pretensão em analisar o tema aqui proposto em profundidade, R. Fac. Dir. UFG, v. 41, n.1, p. 125-141, jan. / jun. 2017 
observando seus diferentes aspectos - jurídico e socioambiental -, de modo a explicá-lo de maneira mais integrada e analítica possível.

\section{A DIVERSIDADE NATURAL BRASILEIRA - BIODIVERSIDADE - E OS SEUS REFLEXOS ECOLÓGICO-CONSTITUCIONAIS}

Um meio ambiente ecologicamente equilibrado é necessário para a existência de toda forma de vida, seja ela humana ou não humana. Juridicamente, o reconhecimento de tamanha importância, no contexto brasileiro, foi albergado no texto da Constituição de 1988 $(\mathrm{CF} / 88)$, que pela primeira vez trouxe um capítulo inteiramente dedicado a esta temática. Em seu artigo 225, caput, enaltece o direito de todos ao meio ambiente referido, bem de uso comum do povo e necessário a sadia qualidade de vida. Tal direito também é destacado como um dever pela $\mathrm{CF} / 88$, uma vez que "se impõe ao Poder Público e à coletividade o dever de defendê-lo e preservá-lo para as presentes e futuras gerações” (BRASIL, 2008, p. 139).

Sob a perspectiva natural, o meio ambiente brasileiro é composto por uma significativa diversidade natural - biodiversidade - tornando o Brasil o principal país megabiodiverso do mundo. Conforme a Convenção sobre a Diversidade Biológica (CDB) entende-se por biodiversidade - diversidade biológica - "a variabilidade de organismos vivos de todas as origens, compreendendo, dentro outros, os ecossistemas terrestres, marinhos e outros ecossistemas aquáticos e os complexos ecológicos de que fazem parte". Compreende também "a diversidade dentro de espécies, entre espécies e de ecossistemas" (CDB, 1992).

Este título de país megabiodiverso decorre das características da biodiversidade brasileira, que compõe um cenário de imenso valor ambiental distribuídos na sua dimensão continental com 8,5 milhões de $\mathrm{km}^{2}$ - quase metade da América do Sul. Consequência desta extensão territorial pode ser percebida no clima, pois abarca diferentes zonas climáticas trópico úmido no Norte, o semi-árido no Nordeste e as áreas temperadas no Sul, por exemplo. Das diferenças climáticas, delineiam-se diferentes biomas, dentre eles a Floresta Amazônica maior floresta tropical úmida do mundo -; o Pantanal - maior planície inundável -; o Cerrado de savanas e bosques; a Caatinga de florestas semi-áridas; os campos dos Pampas; e a floresta tropical pluvial da Mata Atlântica. Não bastasse esta riqueza terrestre, o Brasil possui uma costa marinha de 3,5 milhões $\mathrm{km}^{2}$, onde se encontram ecossistemas como recifes de corais, dunas, manguezais, lagoas, estuários e pântanos. Em decorrência destes dados, constata-se 
Direito Ambiental e as Diversidades Natural e Cultural no Brasil: direitos da Sociobiodiversidade e Sustentabilidade na Constituição Brasileira

que o Brasil abriga a maior biodiversidade do planeta, composta por $20 \%$ do número total de espécies da Terra, justificando o citado título (MMA, s.a. p.1).

Algumas destas áreas são constitucionalmente definidas como patrimônio nacional - Floresta Amazônica brasileira, Mata Atlântica, a Serra do Mar, o Pantanal MatoGrossense e a Zona Costeira -, sendo a sua utilização estabelecida na forma da lei e conforme condições que "assegurem a preservação do meio ambiente, inclusive quanto ao uso dos recursos naturais". Tal disposição encontra-se no $\S 4^{\circ}$ do artigo 225 da $\mathrm{CF} / 88$, que vincula à soberania nacional ambiental as referidas áreas com a pretensão em preservá-las, uma vez que se trata de espaços ricos em recursos naturais.

O imenso e biodiverso cenário natural brasileiro ensejou a devida proteção constitucional, pois além de abrigar recursos naturais necessários para a existência da Vida água, por exemplo - também acolhe demais formas de vida e elementos abióticos - solo e temperatura, por exemplo - necessários para a manutenção da "Teia da Vida" (CAPRA, 1996) da qual os seres humanos fazem parte. Diante desta comunidade de seres vivos ecossistema - que Ost (1995, p. 312) apreende as ciências ecológicas explicitadas pelas manifestações de solidariedades para a manutenção da vida como um todo, não havendo dúvida de que o homem é parte integrante desta grande comunidade, que mantém trocas de fluxos de energia e matéria.

O contexto natural acima remete ao termo "ecologia", criado pelo biólogo alemão Ernst Haeckel em 1866, servindo para definir o "estudo do inter-retrorrelacionamento de todos os sistemas vivos e não-vivos entre si com o seu meio ambiente, entendido como uma casa, donde deriva a palavra ecologia (oikos, em grego = casa)” (BOFF, 2005, p. 10). Então, entende-se que as ciências ecológicas estudam as relações que ligam os organismos ao meio em que vivem. Pena-Vega (2010, p. 30-31) ressalta o fato dos sistemas vivos apresentarem-se todos integrados, com isto não sendo possível reduzir as propriedades deste processo em partes menores. Seu princípio fundamental baseia-se na interação, na interdependência que o torna dinâmico, fazendo do ecossistema uma totalidade complexa auto-organizada e autoorganizante, a partir de unidades de interação interconectadas numa rede de relações.

O desenvolvimento da definição de ecologia denota a percepção do meio no qual a humanidade está inserida e de onde ocorrem as inter-relações entre humanos e nãohumanos, traduzidas num vínculo vital para a existência de ambos. Desta apreensão emerge o paradigma ecológico que compreende o homem parte do todo - natureza -, implicando uma R. Fac. Dir. UFG, v. 41, n.1, p. 125-141, jan. / jun. 2017 
mudança de mentalidade e de visão de mundo, onde o humano "é apenas um elemento a mais no ecossistema da natureza, um elo entre muitos na cadeia de reprodução da vida" (JUNGES, 2010, p. 13).

Ciente deste aspecto ecológico que denota o equilíbrio necessário para a manutenção de um meio ambiente apto a garantir a qualidade de vida, que uma das incumbências do Poder Público para efetivar o direito ao meio ambiente ecologicamente equilibrado está previsto no inciso I, do artigo 225 da CF/88. Este dispositivo constitucional destaca a necessidade de preservação e restauração dos processos ecológicos essenciais, assim como o provimento do manejo ecológico das espécies e ecossistemas (BRASIL, 2008, p. 139). Para Milaré (2011, p. 191-192), o enunciado do referido inciso, na primeira parte atenta para a intervenção antrópica no ecossistema, devendo esta ser no sentido de "preservar ou recuperar a sua qualidade, visto que há interesses mútuos entre o meio natural e o ambiente humano". Quanto à segunda parte do inciso I, o citado doutrinador aponta para o trato dos recursos naturais num sentido de gestão ambiental, para conservar e recuperar as espécies, desta forma assegurando o equilíbrio entre comunidade biótica e o seu habitat.

Não bastasse esta previsão constitucional em consonância com a concepção ecológica da biodiversidade, atenta o inciso VII do supracitado artigo para a proteção da fauna e flora, vedando na forma da lei, toda prática que implique em riscos para função ecológica. Da mesma forma, veda práticas que deem causa a extinção de espécies ou submetam os animais a crueldade (BRASIL, 2008, p. 139).

Estes dispositivos constitucionais atentam para o meio ambiente natural, definição esta trazida pela Política Nacional do Meio Ambiente, instituída pela Lei n ${ }^{\circ}$ 6.938/81, que em seu artigo $3^{\circ}$, inciso I definiu meio ambiente como "o conjunto de condições, leis, influências e interações de ordem física, química e biológica, que permite, abriga e rege a vida em todas as suas formas". Quando se fala em meio ambiente na perspectiva natural, trata-se de um dos pilares da sustentabilidade, qual seja, o ambiental, que reflete o equilíbrio da natureza para a existência de vida com qualidade, assim como a existência de recursos naturais suficientes, tanto no presente, quanto no futuro, para sanar as necessidades dos seres humanos e não humanos. Mas, cabe salientar que este mesmo meio abriga não só a vida enquanto espécies biologicamente definidas, pois inserido nele estão os seres humanos e seus desdobramentos sociais, que afetam positiva ou negativamente o ambiente que habitam.

Assim, não basta falar em sustentabilidade apenas sob o viés ambiental, pois além da prudência ecológica, anseia pela relevância social e viabilidade econômica para que um R. Fac. Dir. UFG, v. 41, n.1, p. 125-141, jan. / jun. 2017 
Direito Ambiental e as Diversidades Natural e Cultural no Brasil: direitos da

Sociobiodiversidade e Sustentabilidade na Constituição Brasileira

desenvolvimento realmente sustentável seja estabelecido (SACHS, 2009, p. 35). Para além das consagradas dimensões econômica, social e ambiental, acrescenta Freitas as dimensões jurídico-política e ética, definindo-a como um princípio constitucional que:

[...] determina, com eficácia direta e imediata, a responsabilidade do Estado e da sociedade pela concretização solidária do desenvolvimento material e imaterial, socialmente inclusivo, durável e equânime, ambientalmente limpo, inovador, ético e eficiente, no intuito de assegurar, preferencialmente de modo preventivo e precavido, no presente e no futuro, o direito ao bem-estar (2012, p. 41).

Neste sentido, não se deve realizar uma apreensão compartimentada do complexo contexto da sustentabilidade e suas dimensões fundamentais - ambiental, econômico e social - e demais dimensões supracitadas, porque o desafio em garantir o direito humanofundamental ao meio ambiente ecologicamente equilibrado e o consequente bem-estar para todos demanda a atenção não só a diversidade natural, mas também para a diversidade cultural e seus modos de vida. Para tanto, com o advento da $\mathrm{CF} / 88$, outras definições de meio ambiente podem ser extraídas, dentre elas o meio ambiente cultural e sua diversidade no contexto brasileiro, que será destacado no próximo momento deste trabalho.

\section{O RECONHECIMENTO E PROTEÇÃO CONSTITUCIONAL DA DIVERSIDADE CULTURAL E SEUS MODOS DE VIDA SUSTENTÁVEIS}

Para além da diversidade natural brasileira acima exposta, o País também é percebido em sua diversidade de culturas, uma vez que abriga diferentes povos e os seus conhecimentos e costumes tradicionais, enriquecendo culturalmente o território brasileiro. Este comporta 5,2 milhões de pessoas oriundas de Povos e Comunidades Tradicionais e Agricultores Familiares, dentre eles: seringueiros, pantaneiros, quilombolas, ribeirinhos e mais de 200 povos indígenas, entre outros (MMA, 2011). Cada povo possui os seus modos de vida, muitos deles vinculados a biodiversidade - recursos naturais - presente no local onde habitam, pois é dela que tiram o seu sustento e vinculam a sua identidade cultural, assim transcendendo o valor instrumental-econômico dos recursos naturais. Neste sentido, relevantes as palavras de Vandana Shiva (2003, p. 85) ligando as diversidades - natural e cultural -, evidenciando a diversidade como principal característica da natureza, trazendo 
consigo a estabilidade ecológica a partir de uma "co-evolução de culturas, de formas de vida, e habitats".

Diante desta diversidade cultural que compõe a população brasileira, que a $\mathrm{CF} / 88$ prevê, para além do meio ambiente natural exposto anteriormente, o âmbito que envolve o meio ambiente cultural em seus artigos 215 e 216. Parte-se então para a exposição de alguns aspectos trazidos por ambos os dispositivos constitucionais, que podem ser vinculados a uma apreensão ecológico-social inerente a uma leitura que vincula a diversidade natural à diversidade cultural.

Conforme o artigo 215 da CF/88 compete ao Estado garantir a todos a plenitude do exercício dos direitos culturais, assim como o acesso às fontes da cultura nacional, apoiando e incentivando a valorização e difusão de manifestações culturais. (BRASIL, 2008, p. 135). Tal previsão confere a importância de proteção ao contexto cultural brasileiro, pois resulta deste meio as manifestações do povo compostas de conhecimentos e experiências, que são herdadas de seus antecessores e repassadas adiante, formando ao longo deste processo acumulativo a história cultural brasileira a ser valorizada e preservada. Desta forma, possibilita-se o conhecimento do processo civilizatório brasileiro, que teve como importantes protagonistas os povos indígenas e afro-brasileiros, devendo o Estado, conforme o $\S 1^{\circ}$ do mencionado artigo, proteger as manifestações culturais populares destes povos tradicionais, assim como de outros grupos participantes no processo civilizatório nacional.

Reforçando a necessária proteção ao contexto cultural brasileiro, o $\S 3^{\circ}$ do supracitado artigo estabelece a criação, através de lei, do Plano Nacional de Cultura de forma a integrar as ações do poder público para o desenvolvimento cultural do país. Dentre outras disposições, prevê a valorização da diversidade étnica e regional. Esta diversidade cultural foi então ressaltada no inciso II da Lei $\mathrm{n}^{\circ} 12.343 / 2010$, que instituiu o referido plano com duração de dez anos, como um dos princípios a ser observados.

Para além da diversidade cultural, a Lei acima elenca também como princípio do atual Plano Nacional de Cultura a responsabilidade socioambiental e a valorização da cultura como vetor do desenvolvimento sustentável. Isto evidencia a sustentabilidade e a conexão das suas dimensões, pois diante das implicações ecológico-sociais que envolvem o vínculo humano-ambiental não se pode tratá-los separadamente. Para garantir o equilíbrio ambiental, expande-se a responsabilidade do homem, porque passa a considerar a proteção da natureza, independente da sua utilidade apenas econômica, significando a igualdade entre o que é bom para as futuras gerações da humanidade será também para a integridade do planeta (OST, R. Fac. Dir. UFG, v. 41, n.1, p. 125-141, jan. / jun. 2017 
Direito Ambiental e as Diversidades Natural e Cultural no Brasil: direitos da

Sociobiodiversidade e Sustentabilidade na Constituição Brasileira

1995, p. 314). Nesse sentido, decorrem as palavras de Jonas (2006, p. 229), entendendo o futuro da natureza incluído no futuro da humanidade, pois os interesses humanos coincidem com o resto da vida, onde esta se dá na "pátria terrestre", logo, inseparáveis.

Voltando a CF/88, o seu artigo 216 estabelece o que é considerado patrimônio cultural brasileiro. Este pode ser bens de natureza material e imaterial, tomados individualmente ou em conjunto, e, que em seu conteúdo, portem referências "à identidade, à ação, à memória dos diferentes grupos formadores da sociedade brasileira". Nestes desdobramentos, destaca-se a inclusão das formas de expressão e os modos de criar, fazer e viver, previsões estas contidas nos incisos I e II do citado dispositivo constitucional, que na prática refletem os modos de vida dos povos tradicionais, muitos deles em consonância com a sustentabilidade. Estes modos sustentáveis são ilustrados nas palavras de Vandana-Shiva, que os descreve a partir de um saber vinculado a biodiversidade (2003, p. 85):

[...] criaram uma forma de saber e descobriram maneiras de tirar seu sustento das dádivas da diversidade da natureza, tanto em sua vertente silvestre quanto na domesticada. As comunidades caçadoras e coletoras usam milhares de plantas e animais para obter comida, remédios e teto. As comunidades pastorais, camponesas e pescadores também criaram saber e desenvolveram um modo de vida sustentável com base na diversidade da terra e dos rios, dos lagos e mares.

Além de registrar a marca da história dos diferentes povos brasileiros - diversidade cultural - a cultura de cada povo e seus modos de vida reflete "o meio de adaptação ao diferentes ambientes ecológicos", tratando-se de um processo acumulativo que resulta da experiência das gerações anteriores (LARAIA, 2009, p. 48). Assim sendo, torna-se necessário a capacidade em aprender, pois conforme Laraia (2009, p. 51) "tudo que o homem faz, aprendeu com os seus semelhantes e não decorre de imposições originadas fora da cultura”. Diante disto, decorre a importância em reconhecer, proteger e perpetuar a diversidade cultural, pois dela diferentes conhecimentos contribuem para o uso sustentável da biodiversidade, além de identificarem toda a existência de uma população tradicional.

Neste sentido, a CDB em seu artigo 10, prevê a utilização sustentável de componentes da diversidade biológica, estabelecendo na sua alínea c, que cada Parte Contratante, dentre elas o Brasil, deve "proteger e encorajar a utilização costumeira de recursos biológicos de acordo com práticas culturais tradicionais compatíveis com as exigências de conservação ou utilização sustentável”. 
Diante dos dispositivos constitucionais abordados neste momento, Santilli (2005, p. 75) aponta para o multiculturalismo que os permeia, pois esta proteção constitucional à cultura redunda na "valorização da rica sociobiodiversidade brasileira, e o reconhecimento do papel das expressões culturais de diferentes grupos sociais na formação da identidade cultural brasileira". Em se tratando de multiculturalismo, inerente a esta multiplicidade está a diversidade cultural, que vem a reconhecer a diferença e o direito à diferença, evidenciando a tendência da $\mathrm{CF} / 88$ em seguir o multiculturalismo, uma vez que reconhece os "direitos coletivos a povos indígenas e quilombolas como povos cultural e etnicamente diferenciados". Rompe-se com a ideologia integracionista prevista no Código Civil e do Estatuto do Índio, que preveem a adaptação à civilização do país, como pretensão a ser alcançada (SANTILLI, 2005, p. 83).

Neste momento, ao abordar o meio ambiente cultural ressalta-se a dimensão socialcultural da sustentabilidade que em conformidade com os referidos dispositivos constitucionais, não admite um desenvolvimento excludente e desigual, pois assim perpetuase um paradigma insustentável, porque iníquo na garantia dos direitos e deveres constitucionais. Esta desigualdade é conveniente para a lógica econômica, tanto em relação à biodiversidade, quanto as culturas, predominando os interesses econômicos dos países desenvolvidos em detrimento de ambos. Por esta razão, que se faz urgente a efetivação da proteção constitucional dispensada ao meio ambiente e suas diversidades - natural e cultural , que compõe o cenário da sociobiodiversidades brasileira.

Partindo deste anseio, que o próximo momento aproxima a sociobiodiversidade da sustentabilidade, para uma leitura desta a partir da perspectiva sociobiodiversa, com intuito de garantir o direito ao meio ambiente ecologicamente equilibrado em consonâncias com as referidas diversidades. Tratando-se da sustentabilidade enquanto princípio constitucional, que esta deve refletir acerca dos direitos que emanam das diversidades - os direitos da sociobiodiversidade - para a superação de uma paradigma de desenvolvimento copiado dos países desenvolvidos e seus interesses. Pensar em termos de sociobiodiverisdade reflete a realidade brasileira e o seu potencial natural e cultural para delinear um desenvolvimento realmente sustentável, porque condizente com os anseios e direitos da sociobiodiversidade.

\section{DIREITOS DA SOCIOBIODIVERSIDADE E SUSTENTABILIDADE}


Direito Ambiental e as Diversidades Natural e Cultural no Brasil: direitos da Sociobiodiversidade e Sustentabilidade na Constituição Brasileira

Como visto anteriormente, a $\mathrm{CF} / 88$ alberga dispositivos que tratam tanto do meio ambiente natural, quanto do meio ambiente cultural refletindo os dois elementos que formam o conceito de sociobiodiversidade, quais sejam, sociedade-cultura e biodiversidade e suas implicações ecológico-sociais. Tendo em vista o cenário brasileiro rico em diversidades naturais e culturais, atenta-se neste momento para a implicação entre a sociobiodiversidade e sustentabilidade, uma vez que ambos os conceitos possuem estreita ligação, pois os modos de vida do primeiro refletem o segundo. Esta afirmação é elucidada por Araujo (2013, p. 278):

[...] a relação entre o ser humano e seu entorno, isto é, a biodiversidade, propicia o surgimento de culturas que são transmitidas de gerações em gerações, formando um ethos cultural com especificidades bem particulares, isto é, sua sobrevivência no sentido comunitário é pressuposto do uso e conservação da biodiversidade de forma sustentável.

Seguindo nas palavras do referido autor, falar em termos de sociobiodiversidade ressalta "a relação entre o ser humano e a natureza, na qual as práticas sociais de produção ou vivência comunitária revelam modelos próprios e específicos no trato com a biodiversidade", evidenciando uma convivência harmônica e sustentável com o meio ambiente (ARAUJO, 2013, p. 279). Partindo desta realidade, que pode ser percebida em diferentes regiões do Brasil, cada qual com as suas peculiaridades culturais e naturais, uma nova percepção de sustentabilidade pode ser desenvolvida, apontando Pena-Vega (2009, p. 42) para o desafio ambiental do qual o Brasil pode transformar em oportunidade, em consideração as suas características socioambientais. Neste sentido, o país pode tornar-se um importante protagonista na definição de um modelo sustentável de desenvolvimento, a partir das suas condições enquanto país megabiodiverso e detentor de inúmeras culturas, não mais adotando um modelo de desenvolvimento alheio a sua realidade.

Transformar o desafio ambiental em oportunidade, como dito, demanda o atendimento dos pilares fundamentais da sustentabilidade - econômico, ambiental e social em consonância com a sociobiodiversidade do contexto brasileiro. Esta observação encontra fundamento nos entendimentos de Hessel e Morin (2012, p. 13), que apontam para a superação de um modelo estandardizado de desenvolvimento que "ignora as solidariedades, habilidades e saberes das sociedades tradicionais", sendo necessário "repensar e diversificar o desenvolvimento de maneira que ele preserve as solidariedades próprias aos envolvimentos comunitários". Esta pretensa superação confronta a concepção predominante de um R. Fac. Dir. UFG, v. 41, n.1, p. 125-141, jan. / jun. 2017 
desenvolvimento que pressupõe o progresso alheio à realidade complexa do meio ambiente, porque em conformidade apenas com parâmetros econômicos de desenvolvimento. Isso restringe as manobras das nações em desenvolvimento, tendo em vista o aspecto colonial trazido pela ótica dos países desenvolvidos, perpetuando o modelo exploratório de recursos naturais, atualmente, sob uma nova ótica de colonização, qual seja, Norte-tecnologia e Sulbiodiversidade, na guerra pelo mercado mundial (DIERCKXSENS, s.a., p. 215).

De tal modo, a lógica insustentável do mercado acaba influenciando relações sociais, eliminando pluralidades culturais e diversidades naturais, em busca do lucro desmedido em detrimento da qualidade de vida humana e não-humana. Conforme esta lógica os custos ecológicos do presente se tornarão os custos sociais do futuro, pois "a degradação do ecossistema afeta mais fortemente as condições de vida dos menos desfavorecidos" (PENA-VEGA, 2010, p. 44).

Os países menos industrializados, mas detentores da maior parte da biodiversidade do mundo se encontram numa situação em que podem exercer o seu papel de destaque neste contexto ambiental, pois a riqueza natural da sua fauna e flora possui significativo valor econômico. Assim, por necessitarem melhorar a sua capacidade no campo da ciência, tecnologia e finanças para melhor explorar e proteger a sua biodiversidade, muitas condições podem ser impostas aos que pretendem ter acesso a sua riqueza natural, condições estas que assegurem os seus direitos - direitos da sociobiodiversidade. No conjunto das exigências, inclui-se a justa e equitativa repartição de benefícios e a transferência de tecnologia, condições essas que desagradam o interesse de grandes empresas transnacionais localizadas nos países desenvolvidos, como os Estados Unidos (DUTFIELD, 2004, p. 60).

Outro ponto a ser ressaltado acerca da sociobiodiversidade diz respeito aos conhecimentos tradicionais atrelados a biodiversidade e que também chamam a atenção dos países desenvolvidos, mais especificamente suas grandes indústrias farmacêuticas. Diante de uma possível apropriação destes conhecimentos para a exploração da biodiversidade, degradando o meio ambiente natural e afetando as diferentes culturas e seus modos de vida direitos da sociobiodiverisdade -, que então uma apreensão sociobiodiversa dos referidos dispositivos constitucionais deve ser realizada para a efetiva proteção das diversidades natural e cultural.

Conforme Araujo (2013, p. 285) o contexto acima que envolve os conhecimentos dos povos tradicionais destaca uma titularidade coletiva, onde o bem imaterial conhecimento tradicional - "é transmitido de geração a geração, que podem livremente R. Fac. Dir. UFG, v. 41, n.1, p. 125-141, jan. / jun. 2017 
Direito Ambiental e as Diversidades Natural e Cultural no Brasil: direitos da Sociobiodiversidade e Sustentabilidade na Constituição Brasileira

disporem dele, sem prestar contas ou pagar pelo seu uso", o que denota uma "noção de propriedade totalmente diferenciada do que é expressa pelas normas contidas nos códigos de direito civil, pois estas sempre evocam o sentido individual de posse, enquanto aquela é construída a partir de valores, costumes e usos compartilhados por toda a coletividade".

Expostos os dispositivos constitucionais que se vinculam a uma percepção da sociobiodversidade, destaca-se também a legislação infraconstitucional neste sentido, que em seu conteúdo incorporam o socioambientalismo. Dentre elas encontra-se a Lei 9.985/2000, que institui o Sistema Nacional de Unidades de Conservação (Snuc), regulamentando o artigo $225, \S 1^{\circ}$ e seus incisos I, II, III e VII da CF/88, instaura a proteção a bens ambientais materiais, ou seja, o reconhecimento através desta lei da conservação e uso sustentável da biodiversidade. Além da definição de biodiversidade, a referida Lei articula esta ao aspecto social-cultural, pois não prevê apenas a manutenção da riqueza natural brasileira, uma vez que se preocupa com "proteção dos recursos naturais necessários à subsistência de populações tradicionais, respeitando e valorizando seu conhecimento e sua cultura e promovendo-os social e economicamente" (SANTILLI, 2005, p. 124).

Diante de todo este complexo contexto ecológico-social, que envolve a biodiversidade e os conhecimentos tradicionais atrelados a ela, delineia-se o conceito de sociobiodiversidade para reforçar a sustentabilidade vinculada à realidade de países megabiodiversos como o Brasil. Da percepção integrada entre os recursos naturais e o aspecto social-cultural que estes trazem consigo e que refletem os direitos da sociobiodiversidade, o Direito é desafiado a ir além de um saber compartimentado vinculado à lei e a determinadas posturas políticas convenientes ao interesse do mercado. Tratar de estabelecer o devido reconhecimento e proteção aos direitos da sociobiodiversidade demanda um esforço em apreender a complexa e dinâmica realidade das implicações ecológico-sociais inerentes ao vínculo humano-ambiental, ou seja, culturas e biodiversidades associadas, onde proteger a integridade das diversidades de uma reflete na outra e vice-versa.

Diante de um embate de percepções que configuram uma distinção de direitos, o individual versus coletivo, surge também um confronto entre dois modelos de uso dos recursos naturais. O primeiro, urbano-industrial desenvolvimentista, baseado na utilização intensiva dos recursos, tanto para a indústria (minérios, madeira, etc.,), quanto na agricultura extensiva e intensiva, revela um padrão insustentável de produção. No segundo, as comunidades locais, que vivem do extrativismo, da agricultura de subsistência, da pesca, cuja R. Fac. Dir. UFG, v. 41, n.1, p. 125-141, jan. / jun. 2017 
utilização dos recursos revela modos de vida sustentáveis, sendo o território ocupado a partir de formas próprias de organização social, onde o que prevalece é o sentido coletivo.

Desse modo, a reflexão converge para uma estrutura jurídica que reflita essa realidade, no sentido de valorizar a multiplicidade de direitos exercidos pelas populações tradicionais - incluindo-se aí não só os indígenas, mas também os quilombolas e os povos ribeirinhos, e tantos outros grupos. Estes criam regras a partir de suas práticas vivenciais com o entorno natural, independentemente das normas estatais incidentes, inclusive contrariandoas em alguns aspectos, notadamente naqueles que digam respeito ao uso e ocupação do espaço e os seus elementos.

Frente aos direitos da sociobiodiversidade, destaca Araujo (2013, p. 288) a possibilidade de estabelecer um direito que seja "reflexivo diante dos modelos tradicionais, postulando-se assim uma nova percepção, onde os saberes herdados de nossos ancestrais permitam a construção de um direito, que antes de tudo seja coletivo, decorrente de uma práxis que se firma como social e ambiental”. Deve então o Direito aceitar o desafio de garantir o direito ao meio ambiente ecologicamente equilibrado, auferindo proteção e efetivação aos "novos" direitos oriundos do reconhecimento da diversidade cultural vinculada à diversidade natural, ou seja, a proteção da sociobiodiversidade enquanto realidade e conceito a ser considerado pela sustentabilidade a ser promovida num país como o Brasil.

\section{CONSIDERAÇÕES FINAIS}

Percebe-se, através dos dispositivos constitucionais expostos neste trabalho, que o direito ao meio ambiente ecologicamente equilibrado e a sustentabilidade podem ser apreendidos a partir de uma percepção trazida pela consideração da sociobiodiversidade. Esta traduz o cenário de países como o Brasil, que em seu território abriga tanto diversidades naturais, quanto diversidades culturais. Partindo desta realidade, que a Lei Maior brasileira traz consigo a tendência em proteger o contexto natural e cultural, uma vez que estes se vinculam aos modos de vida sustentáveis adotados pelos povos tradicionais e seus conhecimentos. Deste cenário sociobiodiverso, que se atenta para as implicações ecológicosociais que permeiam o vínculo humano-ambiental para a compreensão e devida proteção constitucional dos direitos da sociobiodiversidade e efetivação da sustentabilidade enquanto desenvolvimento multidimensional.

Após estes apontamentos, percebe-se que é possível implementar uma compreensão R. Fac. Dir. UFG, v. 41, n.1, p. 125-141, jan. / jun. 2017 
Direito Ambiental e as Diversidades Natural e Cultural no Brasil: direitos da Sociobiodiversidade e Sustentabilidade na Constituição Brasileira

acerca da sustentabilidade a partir de uma percepção da sociobiodiversidade, para ultrapassar modelos de desenvolvimento adotados de outras realidades, que não condizentes com a brasileira. Como visto, conforme o potencial natural e cultural do Brasil, o desafio ambiental pode-se transformar em oportunidade ambiental, elevando o país em sua condição de megabiodiverso e detentor de um rico multiculturalismo e seus modos de vida sustentáveis, tornando-se exemplo de desenvolvimento em consonância com a proteção ambiental e cultural.

Essas reflexões que associam sociobiodiversidade e sustentabilidade atentam para a importância das diversidades - cultural e natural -, de onde emerge também a necessidade de superação da valoração de ambas unicamente pelo viés econômico-utilitário, que exploram os recursos naturais em detrimento da qualidade de vida de muitos, para manter o consumo de poucos. Tanto ecologicamente quanto politicamente deve-se superar a uniformidade para ir ao encontro da diversidade, porque é da consideração desta que se respeitam os direitos de todos em função da sua cultura, tornando o desenvolvimento realmente sustentável para todos. Da pretensão em estabelecer uma existência dialogada entre as diversidades é necessária a apreensão da complexidade ambiental para constituir um cenário sustentável, decorrente da leitura integrada dos dispositivos constitucionais numa tentativa de apreender a vinculação da sustentabilidade e sociobiodiversidade.

\section{REFERÊNCIAS}

ARAUJO, Luiz Ernani Bonesso de. O direito da sociobiodiversidade. In: Direitos Emergentes na Sociedade Global: anuário do Programa de Pós-Graduação em Direito da UFSM. Org. Jerônimo Siqueira Tybusch; Luiz Ernani Bonesso de Araujo; Rosane Leal da Silva. Ijuí: Unijuí, 2013, pp. 269-291.

BRASIL. Constituição Federal de 1988. In: Coletânea de Direito Internacional, Constituição Federal. Org. Valerio de Oliveira Mazzuoli. 6 ed., rev., ampl. e atual. São Paulo: Revista dos Tribunais, 2008.

BRASIL. Lei $\mathbf{n}^{\circ}$ 6.938/1981. Dispõe sobre a Política Nacional do Meio Ambiente, seus fins e mecanismos de formulação e aplicação, e dá outras providências. Disponível em: <http://www.planalto.gov.br/ccivil_03/leis/16938.htm> Acesso em 5 de jan. 2014.

BRASIL. Lei 9.985/2000. Regulamento o artigo 225, $\S 1^{\circ}$, incisos I, II, III e VII da Constituição Federal, institui o Sistema Nacional de Unidades de Conservação da Natureza e dá outras providências. Disponível em: <http://www.planalto.gov.br/ccivil_03/leis/19985.htm> Acesso em: 7 de mai. 2014. 
BRASIL. Lei $\mathbf{n}^{\circ}$ 12.343/2010. Institui o Plano Nacional de Cultura - PNC, cria o Sistema Nacional de Informações e Indicadores Culturais - SNIIC e dá outras providências. Disponível em: <http://www.planalto.gov.br/ccivil_03/_ato2007-2010/2010/lei/112343.htm> Acesso em 5 de jan. 2014.

BOFF, Leonardo. Ética da Vida. Rio de Janeiro: Sextante, 2005.

CAPRA, Fritjof. A teia da vida. São Paulo: Cultrix, 1996.

CDB. Convenção sobre a Diversidade Biológica. Disponível em: <http://www.mma.gov.br/estruturas/sbf_dpg/_arquivos/cdbport.pdf> Acesso em: 5 dez. 2013.

DIERCKXSENS, Wim. IV Outro mundo es posible; el conocimiento como patrimônio de la humanidade. In: Nuevos colonialismos del capital: propriedade intelectual, biodiversidade y derechos de los pueblos. Barcelona: Icaria, s.a.

DUTFIELD, Graham. Repartindo benefícios da biodiversidade: qual o papel do sistema de patentes? In: Diversidade Biológica e conhecimentos tradicionais. Org. Marcelo Dias Varella; Ana Flávia Barros Platiau. Belo Horizonte: Del Rey, 2004, pp. 57-107.

FREITAS, Juarez. Sustentabilidade: direito ao futuro. 2. ed. Belo Horizonte: Fórum, 2012.

HESSEL, Stéphane; MORIN, Edgar. O caminho da esperança. Trad. Edgar de Assis Carvalho; Mariz Perassi Bosco. Rio de Janeiro: Bertrand Brasil, 2012.

JONAS, Hans. O princípio responsabilidade: ensaio de uma ética para a civilização tecnológica. Trad. Marijane Lisboa; Luiz Barros Montez. Rio de Janeiro: Contraponto PUCRio, 2006.

JUNGES, Jose Roque. (Bio)Ética Ambiental. São Leopoldo: UNISINOS, 2010.

LARAIA, Roque de Barros. Cultura: um conceito antropológico. 23 ed. Rio de Janeiro: Jorge Zahar, 2009.

MILARÉ, Édis. Direito do ambiente: a gestão ambiental em foco: doutrina, jurisprudência, glossário. 7 ed., rev., atual., e reform. São Paulo: Revista dos Tribunais, 2011.

MMA, Ministério do Meio Ambiente. Sociobiodiversidade no Brasil. 2011. Disponível em: $<$ http://www.mma.gov.br/estruturas/sds_dads_agroextra/_arquivos/apresentaosociobiodiversi dade2011_65.pdf> Acesso em: 5 dez. 2013.

MMA, Ministério do Meio Ambiente. Biodiversidade Brasileira. s.a. Disponível em: <http://www.mma.gov.br/biodiversidade/biodiversidade-brasileira> Acesso em: 5 dez. 2013.

OST, François. A natureza a margem da lei a ecologia à prova do direito. Instituto Piaget, 1995. 
Direito Ambiental e as Diversidades Natural e Cultural no Brasil: direitos da Sociobiodiversidade e Sustentabilidade na Constituição Brasileira

PENA-VEGA, Alfredo. O despertar ecológico: Edgar Morin e a ecologia complexa. Trad. Renato Carvalheira do Nascimento e Elimar Pinheiro do Nascimento. Rio de Janeiro: Garamond, 2010.

SACHS, Ignacy. Caminhos para o desenvolvimento sustentável. Org. Paula Yone Stroh. Rio de Janeiro: Garamond, 2009.

SANTILLI, Juliana. Socioambientalismo e novos direitos. São Paulo: Peirópolis, 2005.

SHIVA, Vandana. Monoculturas da Mente: perspectivas da biodiversidade e da biotecnologia. Trad. Dinah de Abreu Azevedo. São Paulo: Gaia, 2003. 